\title{
Communication Skills Course in Bridging the Gap of Weak Students' Communicative Competence and Accentuating Performance: A Case of Sokoine University of Agriculture
}

\author{
Job Wilson Mwakapina \\ Department of Language Studies, Sokoine University of Agriculture, Morogoro, Tanzania \\ Email address: \\ jvdmwakapina@gmail.com \\ To cite this article: \\ Job Wilson Mwakapina. Communication Skills Course in Bridging the Gap of Weak Students' Communicative Competence and \\ Accentuating Performance: A Case of Sokoine University of Agriculture. International Journal of Language and Linguistics. \\ Vol. 8, No. 1, 2020, pp. 1-10. doi: 10.11648/j.ijl1.20200801.11
}

Received: December 9, 2019; Accepted: December 21, 2019; Published: January 6, 2020

\begin{abstract}
This paper reports the findings on the effectiveness of Communication Skills (CS) course in boosting students' communication competence at Sokoine University of Agriculture (SUA). In particular, the study determined whether there is a relationship between the ability in the CS and performance in other courses offered at the university. It also assessed the impact of the course on the students' performance in other courses of their specialty after the training of the course, and lastly, it gauged the extent of effectiveness of the course. The study involved instructors and students and were obtained through random and purposive sampling procedures. Data for the study were collected using questionnaires, interviews and documentary reviews, and were treated qualitatively and quantitatively. The findings show that the course is not much effective at boosting students' communication competence. Furthermore, it is revealed that there is no relationship between the CS course and other courses. This is perhaps the least anticipated result of all because one of the key objectives for teaching CS course is for it to help students to perform better in other courses of their specialization. Instead of simply concluding that CS and other courses are not connected or there is no impact of CS on other courses, there is a need of considering exceptional factors which have led to the situation. Of course, improved performance because of CS is expected, but based on these findings, there is no clear effect, partly would be because most of the non-CS instructors are being concerned much with the material content of their courses, rather than the grammatical/CS parts when evaluating students' works. This makes CS components not reflected in the students' performance of most of the courses. The study urges the government to improve and expand infrastructures to match with enrollment. Again, it needs to hire more academic staff and retain them through improving their salaries, incentives and payments of their demands to remedy the problem of high teacher-students ratio which is currently alarming.
\end{abstract}

Keywords: Communication Skills, Effectiveness, English Grammar, Communicative Competence

\section{Background of the Study}

In Tanzania, many students have been facing problems of communication in English when they join higher education. To minimize the problems, CS courses were introduced in all universities in the country. For the first time, the CS course was introduced at the University of Dar es Salaam (UDSM) in 1978 [1, 2]. The introduction of the CS courses in universities and colleges aimed at aiding students to improve their abilities to learn other courses efficiently and effectively, as well as communicating effectively through
English in and out of their specialized subjects [1]. In this regard, in many universities in the country, the CS course has been taught for many years. However, still, there are many outcries from scholars [such as 4, 5, 6] and the general public that many of the graduates cannot express themselves well in speech and writing through the English language even after the training [3]. It seems CS course taught in universities in the country is not making any headway in enhancing effective students' communication.

This problem is not inherent only in Tanzania. Various researchers from different countries report a lack of or low 
communicative competence in English among school and higher education graduates even after CS training has taken place. For example, Al-Toubi conducted a study in Oman and found that the Omani curriculum failed to prepare learners for effective communication in English [7]. Similarly, AlMahrooqi and Denman realized that despite having been taught when they were at college, employees largely lacked communication competencies, necessary to succeed in workplaces [8]. Moreover, Al-Issa in Oman and Moody in Arabian Gulf, as well as Lukmani in India, and Hyland in Hong Kong China report similar findings [9-12]. Based on the findings, it seems that the course is not effective in addressing students' language and CS weaknesses.

Currently, at Sokoine University of Agriculture (SUA), the course is taught to all the first-year undergraduate students and is offered in two semesters, semester one as Communication Skills1 (CS I), which functions as a remedy to those found to have a weak English Language Proficiency (ELP) at the point of entry. In semester two, it is called Communication Skills II (CS II) and is offered to help students develop mainly study skills particularly in writing, speaking, reading and listening. Nevertheless, at the university, as time goes on, the problem of poor CS among the students becomes more intensive, as reflected during seminar presentations, when dealing with assignments, tests and special project reports as well as during communication outside the classroom where Swahili and code-mixing are predominant instead of English, which is the Language of Instruction (LoI).

CS course is not all about the English language or the grammar of English. In the Tanzanian university context, most people confuse CS and English language or the grammar of the English language. CS are all about the skills of communicating efficiently and effectively in all situations. Again, CS can be a set of skills that enable a person to convey information, so that it is received and understood. In a way, people confuse the two, CS and the grammar of English, because the skills of becoming effective in communication are based in English since the LoI in Higher Learning Institutions (HLIs) is English. According to Mohamed communication skills refer to the skills in communication, which can be in any language, and the learner of CS is assumed to have mastered the target language and $\mathrm{s} /$ he only lacks the techniques in particular domains of use [13]. Thus, a CS course is not about the English language or the grammar of English, but in it, there can be one module or two on the English grammar.

Furthermore, English grammar refers to the rules of the structure of the English language. In Tanzanian university context, students, apart from those who take English language at that level as their specialty, are taught the grammar of English, because many at the point of entry to university are realized to have very low ELP, so to help them English grammar is taught as part of the CS courses, and that is the base for the confusion. Thus, a CS course can subsume the grammar of a language, while a Study Skills course can be like a CS course, but it mainly focuses on studies per se.
Many of the study skills are relevant to studying. Therefore, in this paper, the two terms, CS and study skills are used interchangeably to refer to skills taught in HLIs to help learners be able to communicate effectively during their studies and at workplaces after graduation.

The expected learning outcomes (as reviewed from the CS course outlines) for teaching the CS course at SUA are as follows: a student at the end of the course should be able first, to demonstrate ability in studying, communicating and gathering information for study purposes. Second, to demonstrate ability in academic literacy skills especially in coping with advanced academic communication, and lastly, should be able to demonstrate ability in applying the study skills/ CS in their specialized subject areas [14]. In line with these expectations, this study sought to assess whether the CS course is taught effectively at SUA. Specifically, the study determined whether there is a relationship of performance in the CS and in other courses offered at the university. Also, it assessed the extent to which the CS learned in the first year has been helping students to perform better in their subsequent years after attending the course. Lastly, the study determined the extent of effectiveness of the course in attaining the goal for teaching and learning it.

\section{Problem Statement}

Scholars [6, 8-12] report that in their countries even after students were taught CS, still they manifest weaknesses after the training. In Tanzania, correspondingly, the CS course has been taught in universities for many years. Despite it being taught for many years, still many of the continuing students even after learning it, seem not to be able to communicate effectively. It seems the impact of the course on students' communicative competence and in other courses of students' specialization is very low. This means that students enter a second year of their studies, while the objectives of teaching CS being unmet or the change being negligible to the extent that it cannot be realized in the subsequent years of students' studies. This conundrum is a predicament that has not been clearly established through research. Thus, this study intended to fill that gap. Specifically, the study had two nullifiable hypotheses $\left(\mathrm{H}_{0}\right)$ to test: 1$)$ there is no relationship between performance in CS course and in other courses offered at the university. 2) The CS course that is taught to first-year undergraduate university students does not help them to perform better in their specialized courses in the subsequent years of their studies. The general assumption here was that the CS course, which is taught to undergraduate university students, does not help them to be effective in communication and to perform better in their specialized programs.

\section{Theoretical Underpinnings}

\subsection{CS Course in Influencing Students' Communicative Competence}

Currently, communicative competence has been the goal of 
every language or CS teaching class. Canale, and Canale together with Swain look at the term communicative competence as a synthesis of an underlying system of knowledge and skill needed for communication $[15,16]$. On the one hand, they consider knowledge to refer to a conscious or unconscious individual's understanding about language and other aspects of language use. Furthermore, they categorized knowledge into three types: knowledge of underlying grammatical principles, knowledge of how to use language in a social context and knowledge of how to combine utterances and communicative functions with respect to discourse principles. On the other hand, they consider the concept of skill to refer to how an individual can use the knowledge in actual communication. Based on the conceptualization of the term communicative competence by Canale, and Canale together with Swain, in this study, communicative competence is simply defined as the ability to communicate effectively and appropriately in all situations.

Various studies have attempted to assess the impact of CS courses in enhancing students' communicative competence or communication abilities and academic performance. For example, Mcha and Rea investigated whether students enrolled in the CS course would improve their language and study skills to a greater extent than those who did not take the course [2]. It was realized that instruction in CS in English does not contribute to better performance in a study skills type of examination, but led to an improvement in the areas of reading and note-taking. On the contrary, Komba realized that majority of students did not employ writing techniques during lectures and that students still exhibited deficiencies in writing skills even after doing the course [17]. Furthermore, Mbowe focused on a lack of interest in CS courses among students in technical training institutions in Tanzania [18]. He indicates that lack of textbooks and other instructional materials, lack of relevant syllabus in relation to students' needs and theoretical nature of the course were the main factors for students' lack of interest in the course. Additionally, Msuya investigated on the relevance and effectiveness of CS course teaching at the UDSM [6]. The findings of his study indicated that the course proved more relevant to the students' needs, but it was inclined towards general academic language and that the overall students' baseline proficiency was generally low even after the instruction. Therefore, there is no noticeable study that has explored well on the effectiveness of CS course in attaining its objectives, particularly by assessing the ability of the course to influence communicative competence and performance in other courses of students' specialization in the subsequent years after students have learned the course in their first year.

\subsection{Effect of the CS on Other Courses}

If one revisits CS teaching guidelines or the course outlines, be it for CS I or CS II of SUA will realize that both show that the course influences other courses studied at the university [14]. For example, if one goes through the course outlines will realize that the learning outcomes of CS II are such as: first, by the end of the learning process, a student should be able to demonstrate ability in studying, communicating and gathering information for study purposes. Second, a student should be able to demonstrate ability in academic literacy skills especially in coping with advanced academic communication. Third, a student should demonstrate the ability in applying the study skills in their specialized subject areas of study at the university. Basing on these learning outcomes, it shows that if students learn CS well, it will help them in their specialized degree program. Therefore, CS as a course is paramount as it provides students with grammar, reading, listening, writing and oral presentation skills which are also needed in students' specialized programs.

Mostly, it is understood that in many universities and colleges where the CS courses are taught, many students still manifest weak communicative abilities $[6,9-12,17]$. Due to this, there might be a danger that the skills that are taught do not help students or their impact is low to influence noticeable changes in the learners. As a result, there is a high possibility that CS courses are not effective or do not produce the desired results to meet students' needs in bridging the gap of weak communication competence. Therefore, it is this gap of knowledge that propelled this study to examine whether the CS course taught at SUA is effective in meeting the desired outcomes.

\section{Study Methodology}

\subsection{Study Area and Sample}

The study was conducted at SUA. The respondents of the study were lecturers and the third-year students who were pursuing a Bachelor of Science with Education (BSc.Ed.). A total of 150 informants informed the study. The informants were obtained through random and purposive sampling procedures. In the sample of 145 were the third-year education students who took different subject combinations (Chemistry + Biology $=40 ;$ Geography + Biology $=35$; Chemistry + Mathematics=20; Geography + Mathematics $=25$; Information + Mathematics $=15 \&$ Applied Extension Education=10) and 5 (five) were lecturers, three were CS lecturers and two lecturers of other courses part from the CS course. The justification for involving lecturers of other courses was to get their views on students' applicability of the skills or usefulness of the skills in other courses of students' specialization after the training of the skills. Students were randomly selected, while instructors were purposively chosen. In particular, any third-year student studying BSc. Ed program was eligible inasmuch as his/her results/scores for CS were found in the university examination results record system, and instructors were purposively chosen, those teaching the CS course and those teaching other courses of students' specialization because they fitted the purpose of the study and the profile of the people the study needed to research.

Also, the choice of the study area focused on the fact that 
the CS department which for now is renamed as, Department of Language Studies, was under intense criticism from other members of staff and the university at large that it has failed to solve students' communication problems because many students still seemed to manifest deficiencies even after the training [19]. Also, as observed by Mwakapina and Mhandeni many employers in Tanzania send an outcry that most of the university graduates in Tanzania cannot communicate well, despite having been taught CS, when they were at college or university [3]. Therefore, due to these complaints, it was the right time to evaluate whether the CS course taught at one of the universities enhances students' communication competence and academic success.

\subsection{Research Design}

The study used a mixed methods design. The mixed methods design combines quantitative and qualitative data in a single research study. Qualitative data tend to be open-ended without predetermined responses, while quantitative data usually include close-ended responses such as those found on questionnaires [20]. Thus, in this study, the qualitative data findings were used to enhance, expand, illustrate, or clarify findings derived from quantitative data which in this study was the primary component. The choice of this research design was based on the purpose of the study, so there was a feeling that either quantitative or qualitative alone will not give a more complete understanding of the problem researched, since some of the previous studies which were mainly qualitative for example, Komba indicated that the course is effective or useful, while complaints from the general public that the course does not seem to address students communication deficiencies were and are still cropping up [21]. Thus, quantitative methods involved correlation and regression analyses. Specifically, correlation analysis was explicitly used when the two variables, ability in the $\mathrm{CS}$ and performance in other courses (core education courses) needed to be related. Also, when the impact of the course on other courses was to be realized, regression analysis was used. Thus, the two, correlation and regression analyses were accomplished by finding coefficient of correlation (r) and coefficient of determination $\left(\mathrm{r}^{2}\right)$ respectively.

\subsection{Methods \& Instruments}

Instruments and methods for data collection included questionnaires, interviews and documentary reviews. Interviews were used in interviewing lecturers and documentary review was used to review the examination results of the CS course and results for core education courses studied by the sampled students. CS scores used are those for CS II course. The scores for the CS were those of the 2012/2013 academic year when the same sampled students were in the first year. This is because CS is only taught in the first year of the undergraduate students, and the assumption is, once it is taught, it will help students in all the subsequent years of their studies. Additionally, Confidential Teaching Evaluation Forms (CTEFs) of CS were also reviewed. The CTEFs are evaluation forms that students are given at the end of each semester of learning to evaluate or rate the teaching and learning process of different courses. The CTEFs used in this study were used by the same sampled student to evaluate the CS course taught to them in the academic year of 2012/2013 when they were in the first year of their studies. The CTEFs were useful in supplementing information to the process of assessing whether the CS course was taught / is taught effectively and efficiently at the university.

\subsection{Data Analysis and Processing}

There were various sorts of data that were collected and thus the analysis involved multiple methods. The data collected were analyzed quantitatively with the help of the Statistical Package for Social Sciences (SPSS) software. Although, before SPSS being used, the analysis of data required several closely related operations such as the establishment of categories. Eventually, these categories were useful to reach data editing, coding, tabulation, and then drawing statistical inferences. Thus, through SPSS the scores of the same students in CS, when they were in the first year, and their scores in other courses (the core education courses) in 2015 when they were in the third year of their studies were compared by finding out the coefficient correlation $=$ ' $r$ ' and were regressed to determine coefficient of determination $={ }^{\prime}{ }^{2}$, which is the influence of CS on students' performance in core education courses. A correlation coefficient measures the strength and direction of a linear association between two variables, and it ranges from -1 to +1 or lies between +1 [22]. Furthermore, the closer the absolute value is to +1 , the stronger the relationship, and a correlation of zero indicates that there is no linear relationship between the variables [22].

\section{Results}

\subsection{Relationship Between CS and Other Courses}

Correlations analysis indicated in Table1 helped in testing the null hypothesis $\left(\mathrm{H}_{0}\right)$ which states that there is no relationship between ability in CS and academic performance in other courses offered at the university. The score of 145 students for the CS course and the core education courses were correlated. The core education program courses scores were treated as the dependent variable while those of CS were the independent variable or the predicting variable. The results of the relationship were as reflected in Table 1 below.

Table 1. Correlations between Achievements in Core Education Courses and in CS Course $(N=145)$.

\begin{tabular}{|c|c|c|c|c|c|}
\hline Variables & EDU300 & & EDC300 & CS Course & EDP300 \\
\hline \multirow{2}{*}{ Research Project (EDU300) } & Pearson Correlation & 1 & $.541 * *$ & 0.033 & $.442 * *$ \\
\hline & Sig.(2-tailed) & & 0.000 & 0.689 & 0.000 \\
\hline
\end{tabular}




\begin{tabular}{|c|c|c|c|c|c|}
\hline Variables & EDU300 & & EDC300 & CS Course & EDP300 \\
\hline \multirow{2}{*}{$\begin{array}{l}\text { Education Media and } \\
\text { Technology (EDC300) }\end{array}$} & Pearson Correlation & $.541 * *$ & 1 & 0.059 & $.634 * *$ \\
\hline & Sig.(2-tailed) & 0.000 & & 0.478 & 0.000 \\
\hline \multirow{2}{*}{ CS course } & Pearson Correlation & 0.033 & 0.059 & 1 & 0.105 \\
\hline & Sig.(2-tailed) & 0.689 & 0.478 & & 0.208 \\
\hline \multirow{3}{*}{$\begin{array}{l}\text { Counseling \& Special Needs } \\
\text { Education (EDP300) }\end{array}$} & Pearson Correlation & $.442 * *$ & $.634 * *$ & 0.105 & 1 \\
\hline & Sig.(2-tailed) & 0.000 & 0.000 & 0.208 & \\
\hline & $\mathrm{N}$ & 145 & 145 & 145 & 145 \\
\hline
\end{tabular}

** Correlation is significant at the 0.01 level (2-tailed).

From Table 1, relying on the value of the coefficient of correlation of each core course, it is reflected that $\mathrm{r}=0.033$ for EDU300 and CS, $\mathrm{r}=0.059$ for EDC300 and CS, and $\mathrm{r}=0.105$ for EDP300 and CS. R being 0.033, 0.059 and 0.105 is equivalent to saying that the relationship is negligible or there is no relation between education core courses and the CS course. This shows that the $\mathrm{H} 0$ that there is no relationship between ability in CS and academic performance in other courses is accepted. In contrast, correlations of these core subjects amongst themselves reflected to be above average or positive, near a strong relation. For example, $r$ for EDP300 and EDU300 was 0.442, for EDC300 and EDP300 was 0.634 , while on EDC300 and EDU300 was 0.541. Furthermore, in relating these core courses against themselves, it has been realized that they were statistically significant at $\mathrm{p}<0.01=0.000<0.01$ (That is to say, $\mathrm{r}=0.442$, $\mathrm{p}<0.01, \mathrm{r}=0.634, \mathrm{p}<0.01$ and $\mathrm{r}=0.541, \mathrm{p}<0.01)$. This shows that there are other factors apart from CS course that are strongly related to students' performance in their specialized programs at the university.

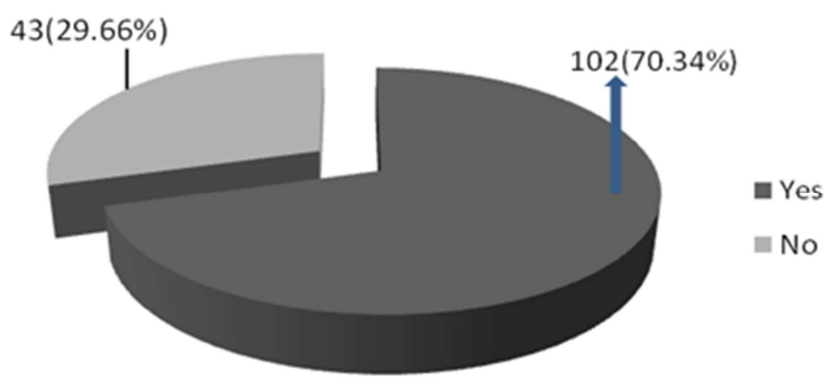

Figure 1. Do you Think Performance in CS Relates to Performance in Other Courses? $(N=145)$.

In addition, the same students whose scores (for CS and core education courses) were reviewed were asked through a questionnaire to tell whether the performance in the CS course relates to the performance in other courses studied at the university. The majority of students pointed out that CS course greatly relates to other courses, while few indicated that they don't see any relationship (see Figure 1). This shows that a large number of students see that performance in other courses is largely related to performance in CS courses, while few did not see such a connection. On the other hand, one of the CS lecturers said:

Communication Skills course was supposed to help students in other courses/ in their specialized programs, but it is not doing or it does less due to teaching large groups and other prevailing classroom obstacles. For instance, a single instructor might be teaching a class of more than 250 students. Just try to imagine, in a class of 250 students, how can a single instructor conduct tutorials? It's impossible!! Thus, the only way the instructor would do is to resort to using lecturing method. (Staff interview, March 2015).

\subsection{Effect of the Course on Other Courses}

The second null hypothesis was that CS that is taught to first-year undergraduate university students does not help them to perform better in their specialized courses in the subsequent years. The analysis of the influence of CS on students' subsequent performance after they have learned CS in the first year was done by calculating the coefficient of determination $\left(r^{2}\right)$. The CS scores of the students were regressed by the scores of the same students in three core education courses.

Table 2 indicates model summaries of regressions of the three core courses of education with the CS course. It is reflected that $r^{2}$ which is the coefficient of determination of the power of CS course in influencing performance in other courses studied at the university is $0.001(0.1 \%)$ in EDU300 course, $0.011(1.1 \%)$ in EDP300 course, and is $0.004(0.4 \%)$ for EDC300 course. Therefore, the power of CS in influencing performance in these core courses being $0.1 \%$, $1.1 \%$, and $0.4 \%$ is too negligible. It is like saying, there is no any effect or its effect cannot be well established. Based on this, the $\mathrm{H}_{0}$ which states that CS that is taught to first-year undergraduate university students does not help them to perform better in their specialized courses in the subsequent years is upheld. This shows that the impact of the CS course on the performance of other courses in the subsequent years of students' studies at the university is very small to the extent that it cannot be noticed. Further, it insinuates that even if CS course would not be there or if students would have not attended the CS course still that could have not affected their overall academic performance in other courses, despite many having low English and communication proficiencies. This was also evident from interviews where one of the non-CS lecturers said: to these science students, when evaluating their works, we normally focus on content, but not on the language of what they write because if you assess their language/communication skills very few would be able to pass because many are not very good at English or communication skills. (Staff interview, March 2015). 
Table 2. Combined Model Summaries of Regressions of CS Scores and Core Education Courses Scores.

\begin{tabular}{|c|c|c|c|}
\hline Model 1 & Regression Summary Model be & urse and EDU300 Course & \\
\hline 1 & $\mathrm{R} \quad \mathrm{R}$ Square & Adjusted R Square & Std. Error of the Estimate \\
\hline 1 & $.033(\mathrm{a})$ & -.006 & 7.95134 \\
\hline Model 2 & Regression Summary Model be & urse and EDP300 Course & \\
\hline 2 & R $\quad$ R Square & Adjusted R Square & Std. Error of the Estimate \\
\hline 2 & .105 (a) & .004 & 8.32185 \\
\hline Model 3 & Regression Summary Model be & urse and EDC 300 Course & \\
\hline 3 & R $\quad$ R Square & Adjusted R Square & Std. Error of the Estimate \\
\hline 3 & .059 (a) & -.003 & 7.86786 \\
\hline
\end{tabular}

Furthermore, in the attempt to explain the extent to which CS has been helping students to perform better in the subsequent years, the same students whose scores were reviewed, were given questionnaires needing them to comment on the usefulness of CS knowledge in report writing or writing

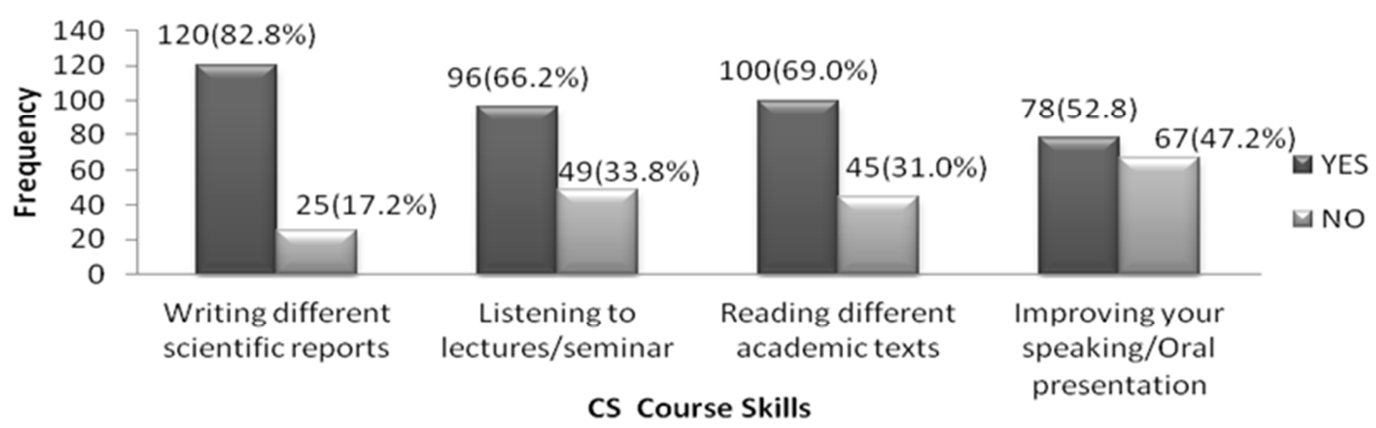

Figure 2. Usefulness of CS Course in Improving Students' Skills.

Similarly, on listening skills, the majority indicated that the CS course does a great job to help them improve their skills in listening to lectures or seminars. Again, on reading skills, the majority indicated that it had helped them, only a few did not see it to be useful. On the speaking skills, although the majority said the course had helped them to improve their speaking skills, the difference between those who said 'yes' and 'no' was minimal. Generally, looking at the figure above, it is shown that the CS course does well in enhancing students' academic writing skills, listening skills, readings skills while on the speaking skills, still serious attention is needed, since the difference between those who said 'yes' and 'no' is very small.

Besides, most of the students said, they are familiar with note-taking techniques and they know that the skill helps them, but they don't use them in taking notes. Connecting this to the interview, one of the lecturers of other courses said, 'despite the students being taught the skills on how to take notes, still, many of them write whatever is spoken by their lecturers'. This means that students do not use the skills learned in the CS courses in taking notes from other lectures which are delivered to them.

\subsection{Efficiency and Effectiveness of CS Teaching}

Apart from assessing the relationship of the course with other courses and the impact of the course in influencing subsequent years' performance in other courses, the study also through questionnaires assessed the efficiency and effectiveness of the CS course teaching at the university. As presented in Figure 3 essays, listening skills and note-taking skills, reading skills and speaking skills. As seen from Figure 2, the majority of students indicated that CS have helped them to be able to write different scientific or academic papers, only very few indicated that they don't see its contribution.

below, $53.8 \%$ of the respondents said 'yes', CS course is effective, whereas $46.2 \%$ said 'no'. Even if many of the respondents among the involved students said CS is effectively taught, this does not guarantee one to say CS is effectively taught because $53.8 \%$ is almost halfway. It is not enough for one to conclude that CS is effectively taught. In addition, the non-CS teaching instructor during interviews said, 'at SUA Communication Skills course is effectively and efficiently taught; the only problem is for CS instructors' overreliance on lecturing as if it is the only method of teaching'.

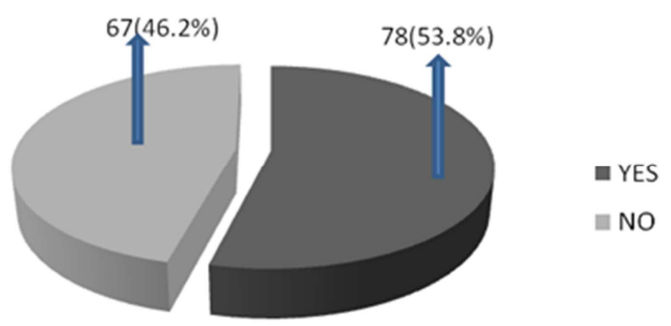

Figure 3. Is the Teaching of CS Course at SUA Effective?

The results from the questionnaires are not much different from those reflected from the analysis of CTEFs. In CTEFs, it is reflected that majority, more than half of the involved students said the course was excellently covered and some indicated that it was very good covered, while few indicated that it was good and the rest (3) $8.6 \%$ indicated it was satisfactorily and poorly covered (see Figure 4 below). Similarly, $51.4 \%$ from CTEFs and $53.8 \%$ from the questionnaires are not much more different. Therefore, in 
terms of what teachers are supposed to cover or do in a classroom, the course is efficiently and effectively covered.

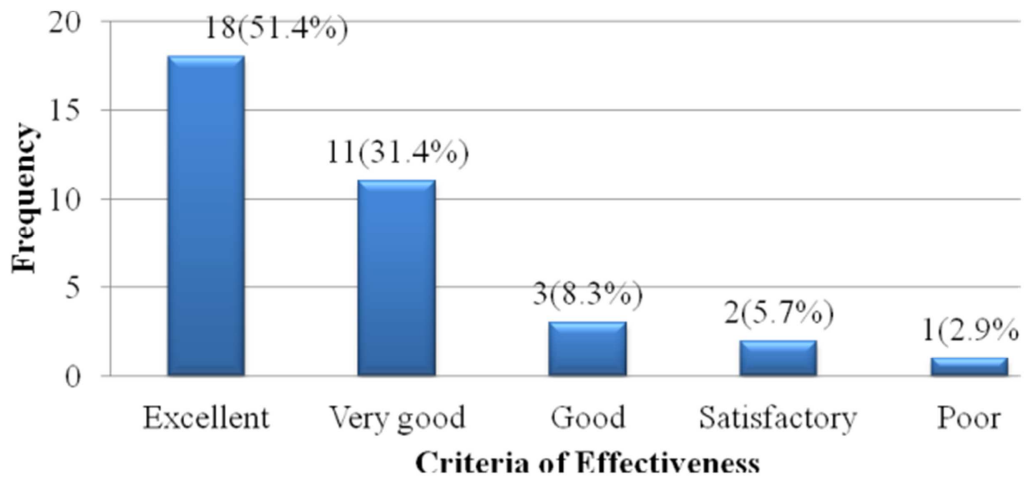

Figure 4. Students' CTEFs Rating of Effectiveness of CS Teaching ( $N=35)$.

Also, in the questionnaires, students were required to indicate methods which their instructors used frequently in teaching the CS course, and if there is efficiency teaching through such methods. As seen from Table 3, most of the students indicated that $\mathrm{CS}$ is mainly taught using lecturing method, while $37.5 \%$ indicated that their lecturers used student-centered methods. On the contrary, on the effectiveness of lecturing method in teaching and learning, the majority of respondents indicated that it was an effective technique. However, on their responses for effectiveness, there is no great difference between the teacher-centered and student-centered methods, as it is on the frequency of use of the two approaches. It is shown that students' centered methods are not used as frequently as teacher-centered methods. Again, teacher-centered methods are higher in effectiveness than the students-centered methods. Based on this result, one cannot imagine that teacher-centered methods are more effective than the students-centered methods because the teacher-centered methods make students passive participants. As a result, they cannot be much effective at enhancing the students' skills. One main reason for many students indicating lecturing method as the effective method might be because is the only technique that they often know since their instructors over-rely on it when teaching the skills.

Table 3. Which Teaching Method did your Teacher Use Frequently in Teaching CS Course? $(N=145)$.

\begin{tabular}{lll}
\hline Teaching methods & Frequency use (\%) & Freq. of effectiveness (\%) \\
\hline Teacher-centered (eg. Lecturing method) & $91(62.50)$ & $82(56.70)$ \\
Student-centered (eg. teamwork, discussions, etc) & $54(37.50)$ & $63(43.30)$ \\
Total (N) & $145(100)$ & $145(100)$ \\
\hline
\end{tabular}

\section{Discussion of the Findings}

The study intended to assess the effectiveness of CS course teaching and learning in universities, a case of SUA. The specific objectives included: finding out the relationship of performance in CS and in other courses offered at the university. Next, it was to determine to what extent the CS course learned in the first-year boosts students' performance in their subsequent years in their specialized programs. Lastly, it was to determine whether the CS course is taught effectively and efficiently. The findings show that there is no relationship or the relationship between the CS course and other courses offered at SUA is very negligible, to the extent that is like saying that there is no relationship. This is perhaps the least anticipated result of all because one of the objectives for teaching the CS courses or the underlying assumption is that the teaching of CS in universities helps students to perform better in other courses studied in the universities since the skills such as listening, writing, reading and speaking are also useful in other courses in listening to lectures, writing proposal or essays and presenting reports in other courses apart from a CS course itself. The question here is why now there is no relationship while the CS course was supposed to be related to other courses? Instead, of simply concluding that CS and other courses studied at the university or education courses are not or less connected, we should rather think of exceptional factors that prevailed in the conduct of the course.

First, it would be because of the failure of students to transfer learning from CS to other courses offered at the university. This is especially true when we base on what most of the students indicated through the questionnaires that CS course is useful in other courses, but most of them do not use the skills after having entered in the subsequent years. Due to this, no any transfer takes place. This finding is in line with Black who realized that either the skills learned and evaluated are not relevant and therefore not transferable, or they are relevant, but students simply fail to transfer them to other courses [23].

Second, it would be because the CS results used have been taken to be static. The CS scores used were those of 2013 when the students were in the first year. The reason for that was because the CS course is only taught in the first year for all the undergraduate students, and students are expected after the training to use the skills in their subsequent years. Assuming that from 2013 when they learned the course and got those score, nothing has changed on their skills 
development that might not be true. In fact, students improve communication abilities as they continue learning or through reading different sources and hearing or listening to English language inputs. Conversely, if they were given the other CS examination to test their current CS abilities possibly that would reflect the existence of a connection. Therefore, administering another CS would be much better. However, that also would contradict with the purpose of this study, because the CS course is only taught in the first year with an assumption that it will help students in any subsequent years of their studies.

Also, it would be because of a difference in test or examination administration environment. The scores of core courses in education are for 2015 while those of CS are for 2013. This difference of two years is big for one to see that the two exams were taken in the same administrative environments. Again, CS course was administered when the students were new to the university learning environment and the core education courses were administered when students were now acquainted with the university learning environment, and they already know how to cope with it. This difference in the administration time for the CS and core courses of education might be one of the attributing factors.

Similarly, as revealed from the study that there is no relationship between the variables, this can be because sometimes examiners tend to adjust their marking schemes based on the overall performance of students, particularly when many students appear to have performed poorly. For example, if many students have failed in a particular subject or course normally instructors or examination boards tend to standardize scores. Thus, if scores have been standardized automatically they do not reflect the true abilities of students in a particular subject or field. Therefore, any of the scores used in this study, if were standardized by the instructors of the courses, might result in the findings revealed in this study.

More significantly, it is clear from the understanding that skills are not transferred to other courses because instructors are not serious at reminding students to use the skills. This would be supplemented by what the non-CS instructors said, 'had I been evaluating both, content and language skills/ communication skills very seriously, very few students would have been passing my tests or exams'. This shows many students pass because language skills or CS components are not considered when lecturers render marks in student's works. When instructors are concerned with only the material content of the subject rather than the grammatical or CS part, the language component/CS components cannot be reflected in the performance of most courses at the university. Thus, if the CS or grammar is not part and parcel of evaluation criteria of students' works, it is possible to reach to this conclusion that CS have nothing to do or are not related to other courses studied at the university.

Nevertheless, there seems to be a doubt here, how can one evaluate only content? It is not known how one can evaluate only the content because if a vessel (language) for carrying a wine (content) is stained, so is the content. It is not true for one to say s/he evaluates only the content of what students write in examinations and leaves away the grammar or other study skills. If at all an instructor evaluates only the content of what students have written that evaluation will be unrealistic.

The finding of this study that CS course at SUA is not related to other courses corroborates with the findings by Kazuzuru who found that CS was highly correlated to Biometry courses (Mathematically based courses) than to Development Studies [24]. This is also a surprising result; the result seems to be against the intuition that CS should be highly correlated to Development Studies, a subject of which its mastery is largely based on language mastery!

On the contrary, Fakeye and Ogunsiji show that the ELP of the students in Nigeria had a significant positive relationship with their overall academic achievement [25]. Therefore, it is obvious that the revealed near-zero relationship in the current study among other factors is because instructors have not been extra vigilant in considering study skills and grammatical parts when evaluating students' works. By doing that, students are not much motivated to struggle more to learn on the skills or transfer the skills to other courses.

The results from the questionnaires reflected a different picture from the results from the correlated and regressed data. From the questionnaires, many of the students perceived the CS course to help them in other courses, but that has no enough evidence statistically with respect to this study. Perhaps, in addition to the aforementioned reasons, CS would perform its job, but it is not doing much because of teaching the theory of the course and neglecting the practical part of it. As such, students are not brought into a true arena of learning and practicing the skills. Consequently, majority of students complete the course while are still lacking the linguistic and communicative competence required for their future academic or professional success at workplaces. This was also evident during interviews when one instructor said, 'many students don't use the knowledge attained from communication skills in other courses after being taught'. I don't know why? But it seems, they have not mastered well the skills'. (March 2015).

The other factor is the teaching of large-classes or highclass sizes. In Tanzania, many of the CS instructors teach classes with so many students. This is posing a great challenge particularly when they want to work with students interactively in the writing process, reading, listening and speaking activities. Such classes become difficult to manage. For example, a single instructor can have a class with more than 300 students. This is because the course is a universitywide course, and also, the government currently has been increasing enrollment yearly, while there is a little or no expansion of resources. Due to this challenge, a communicative teaching and learning approach, which is a highly emphasized as the best approach cannot be well evidenced in the course.

Concerning the effectiveness of CS course teaching, the majority of students indicated that the course was effectively and efficiently taught. Also, the instructors during interviews 
said the course is not much effective. Again, on the effectiveness of the course in influencing good performance in other courses, many students indicated it to be effective, while the majority of the instructors said it is effective to a small extent. Thus, this shows that the course is effective in influencing students' communication competence to a small extent. It is not doing much because of the aforementioned prevailing obstacles in the conduct of the course.

Along the same line, the influence of $\mathrm{CS}$ in the performance of other courses has been revealed to be a very weak influence. This shows that there is no/ there is a very low effect of CS on core education courses. However, about the students' responses in the questionnaires, students indicated that the course is useful in other courses in report writing, listening to lectures, taking notes, essays writing, reading literature, in citing and organizing references and generally in the improvement of day to day communications at the university and workplaces after graduation. Thus, this finding that CS is not related and does not influence the core education courses, which would have seemed to be reasonably related because most of these courses need a mastery of CS to understand them and perform better, shows that even if these students would have not studied CS course, still they would have passed other courses of their specialization. A similar observation was made by Abayo and Mbette who used spearman rank correlation and regression analysis to show the degree of relationship between faculties of commerce and management and engineering [26]. The correlation coefficients were too low to indicate a significant relationship. Therefore, this is no way a by chance event and there are factors, as expounded well above, that have led to this kind of dwindling relationship.

It is clear that because students even after the training manifest weaknesses, one would expect the relationship to be there, but a weak one. As Wilson highlights that the power of ELP in influencing overall performance in secondary schools is low because of students' weaknesses in ELP [5]. In fact, the results of the current study seem to tally well with what is happening now in our surroundings. Most of the university graduates in Tanzania have very good certificates or transcripts that have been ascribed with excellent score/grades or outstanding Gross Point Average (GPA) which most employers would admire, but after interviews, many employers are upset because the graduates do not seem to possess abilities which relate to the grades or GPA ascribed in their transcripts or certificates or do not seem to be able to communicate effectively in English, the language, which was used in their learning process. Thus, this problem originates from so many factors.

\section{Conclusion}

In conclusion, CS course based on what is supposed to be covered in class is effectively covered, though the key objectives are not very well met as students enter in the second year of their studies among other factors being highclass sizes and the teaching of language skills theoretically.
In the recent years, the government has been enrolling so many students in universities while there is little/no expansion of infrastructures and human power. This act has made classes unmanageable and hence the teaching CS communicatively becomes highly challenging. In respect of this, students have been getting little/ no time for practicing the skills. Thus, communicative learning or teaching of the course has become a difficult thing to attain. Furthermore, CS has been found to have no relationship and a very weak influence on other courses offered at the university because of several factors such as non-CS instructors' negligence of evaluating or putting less emphasis on language and CS related items when evaluating students' works, lack of enough students' practices of the skills and a failure of students to transfer CS knowledge to other courses studied at the university.

\section{Recommendations}

This study therefore, recommends the following for the CS course to accentuate positive results on students' skills. First, students need to practice the skills after the training. They need to practice writing commentaries about anything of their favorite, short stories or applying the learned skills such as note-taking, citation and referencing to improve their works/assignments because knowing the skills alone is not enough, they must apply the skills in CS course as well as transferring the skills to their specialized programs. Second, the instructors of the CS courses and those teaching other courses need to work together or cooperate in enhancing students' CS through insisting students to apply the skills, and also by evaluating the language or CS components in students works, since there is no way one will evaluate only the content and ignore the language/ the form which has been used in communicating the content. However, it has been attested through interviews that many of the non-CS instructors do not care about language skills when dealing with either the students or when evaluating works performed by the students. In fact, that kind of evaluation becomes unrealistic, because if the vessel that carries a wine is tainted so will be the wine. Also, the government is urged to hire more academic staff to minimize the teacher-students ratio which is too high at the moment. Language or skills learning is effective when there is an interaction. The teacher-students ratio in many of universities in Tanzania is too high. This makes the communicative teaching of CS turn out to be a nightmare. Again, it needs to employ more staff and find strategies for retaining them. Public universities are experiencing a problem of their academic staff leaving the public sector and joining the private sector or political posts where they get 'greener pasture'. As such, improvement of salaries, incentives and payments of demands of workers or payment of their arrears at the appropriate time will keep the staff in these public sectors; otherwise, the public universities will continue experiencing the problem of high teacher-students ratio or of a private sector pulling staff from public universities. Lastly, the study recommends universities to teach the CS course in all the three 
or four years of the undergraduate education as a spiral form of syllabus, unlike this time when it is taught only in the first year. This will give students time to reflect on what they learn. Teaching the same things with only different levels of difficulty each semester or year will remind students to apply the knowledge in each year of their studies and even at workplaces after graduation.

\section{References}

[1] University of Dar es Salaam, Intensive grammar programme: A workbook in basic grammar for academic purposes, Communication skills Unit, University of Dar es Salaam, 1983.

[2] Y. Y. Mcha, and P. Rea, The impact of communication skills in English courses with special reference to students in the faculty of arts and social sciences. Papers in Education and Development, 1985, vol. 10, pp. 61-64.

[3] J. W. Mwakapina, and A. S. Mhandeni, The influence of language of instruction on students' academic outcomes: The experience of secondary schools in Morogoro, Tanzania, Journal of Africa Tomorrow, 16 (2), pp. 125-148, 2014.

[4] M. K. Osaki, Forces influencing undergraduates' performance in an African University", Perspective in Education, 1997, vol. 13 (3), pp. 145-165.

[5] J. Wilson, English language proficiency and academic achievement in Tanzanian secondary schools, Unpublished M. A Thesis, University of Dar es Salaam, Tanzania, 2011.

[6] E. A. Msuya, Communication Skills course relevance and effectiveness at the University of Dar Es Salaam. Ph. D Thesis, University of Dar es Salaam, Tanzania, 2011.

[7] S. S. Al-Toubi, A Perspective on Change in the Omani ELT Curriculum: Structural to Communicative. Unpublished Master's dissertation, University of Bristol, England, 1998.

[8] R. Al-Mahrooqi, and C. J. Denman, Omani Graduates' English-language Communication Skills in the Workforce: Employees' Perspectives, International Journal of Applied Linguistics \& English Literature, 2016, vol. 5 (4) pp. 172-182.

[9] A. Al-Issa, The implications of implementing a 'flexible' syllabus for ESL Policy, in Sultanate of Oman RELC, 2007, vol. 38 (1), pp199-215.

[10] J. Moody, A neglected aspect of ELT in the Arabian Gulf: Who is communication between? In Zhang, L. J., R. Rubdy, \& Alsagoff, L. (Eds.), Englishes and Literatures-in-English in a Globalized World: Proceedings of the 13th International Conference on English in Southeast Asia (pp. 99-119). Singapore: National Institute of Education, Nanyan Technological University. in Agnitotri, R. K. A. L. Khanna (eds.). English Language Teaching in India, 2009.

[11] Y. Lukmani, "Evaluation of a mainstream innovative language skills course". In Agnitotri, R. K. \& A. L. Khanna (eds.). English Language Teaching in India: Issues and innovations. New Delhi: Sage Publications, 1995.

[12] K. Hyland, "Is EAP necessary?" A survey of Hong Kong undergraduates. Asian Journal of English Language Teaching, 1997, vol. 7 (2), pp. 77-99.

[13] H. I. Mohamed, 'Communication Skills or Communicative grammar of English'. In SUACONE: A Newsletter of Sokoine University of Agriculture Convocation, 2012, vol. 15 November.

[14] Sokoine University of Agriculture, Prospectus for undergraduate students 2012/20113 Morogoro. SUA, 2012.

[15] M. Canale, From communicative competence to communicative language pedagogy. In Richards, J. C., \& Schmidt, R. W. (Eds.), Language and Communication, 2-27. London: Longman, 1983.

[16] M. Canale, and M. Swain, Theoretical bases of communicative approaches to second language teaching and testing. Applied Linguistics, 1980, vol. 1, pp. 1-47.

[17] S. C. Komba, The impact of communication skills course on students' development of communicative abilities. Unpublished M. A. Education, Dissertation. UDSM, Tanzania, 2008.

[18] D. C. Mbowe, (1994). Factors influencing lack of interest in the English communication skills course among students in Tanzanian technical training institutions. Unpublished M. A. Education Thesis. University of Dar es Salaam, Tanzania, 1994.

[19] H. I. Mohamed, Academic writing as social practice: A critical discourse analysis of student writing in higher education in Tanzania. Unpublished Doctoral thesis. University of the Western Cape. Cape Town, 2006.

[20] J. W. Creswell, J. W. 2014. Research design: Qualitative, quantitative, and mixed methods approaches 4th ed. Thousand Oaks, CA: Sage.

[21] S. C. Komba, S. C. The perceived importance of communication skills courses among university students: The case of two universities in Tanzania. International Journal of Education and Research, 2015, vol. 3 (2), pp. 497-508.

[22] R. C. Kothari, Research Methodology, Methods and Techniques, New Delhi, Wiley Eastern Limited, 2004.

[23] J. Black, Performance in English skills Course and Overall Academic Achievement, TESL Canada Journal, 1991, vol. 9 (1), 43-56.

[24] B. Kazuzuru, Introductory Statistics with Basic Mathematics: A Compendium of Statistics and Mathematics, pp 101, Department of Biometry and Mathematics, Faculty of Science, SUA, 2011.

[25] D. Fakeye, and Y. Ogunsiji, "English Language Proficiency as a Predictor of Academic Achievement among ELF students in Nigeria", Journal of Science Research, 2009, vol. 37 (3) pp. 490-495, from http://www.eurojournals.com/ejsr 373 14, [accessed $24^{\text {th }}$ December, 2016].

[26] A. G. Abayo, and T. S. Bwette, "Higher Education Quality: Case Study of University of Dar es Salaam", in Galabawa, J. C. J, K, Senkoro, F. E. M and Lwaitama, A. F (eds.), The Quality of Education in Tanzania, Issues and Experience (7790), Faculty of education, University of Dares Salaam, 2000. 